Patient Education and Counseling, 7 (1985) 345-358

Elsevier Scientific Publishers Ireland Ltd.

\title{
A REVIEW OF HOSPITAL-BASED HEALTH PROMOTION PROGRAMS IN MICHIGAN NON-GOVERNMENTAL HOSPITALS
}

\author{
BETH E. PACK ${ }^{a}$, O. LYNN DENISTON ${ }^{*}, \mathrm{~b}$, SUSAN WEIL BATES ${ }^{c}$ and WILLIAM BEERY ${ }^{\mathbf{d}}$ \\ ${ }^{\mathrm{a}}$ Michigan Department of Health, ${ }^{\mathrm{b}}$ The University of Michigan School of Public Health, \\ ${ }^{\mathrm{c}}$ Michigan Hospital Association and ${ }^{\mathrm{d}}$ Group Health Cooperative of Puget Sound, Ann \\ Arbor, MI (U.S.A.)
}

(Received January 10th, 1985)

(Accepted March 15th, 1985)

\begin{abstract}
In 1983, the 217 hospitals of the Michigan Hospital Association (MHA) were surveyed to learn more about their efforts in health promotion programming. Eighty percent (174 hospitals) responded to the survey, with $48 \%$ reporting on 532 programs. Those programs included 216 in health promotion as defined by the survey instructions, 110 in disease management, 66 in first aid and safety, 87 screening, and 53 miscellaneous education programs. Further particulars about the programs are presented, including information regarding program audience, times offered per year, median enrollment, median participant hours, program age, number and type of educational methods used, follow-up methods, and fees charged.

Hospital administrators' perceptions regarding health promotion programs were also surveyed. They indicated a higher level of interest in providing such programs because they viewed them as a needed community service. Conversely, they did not see them as a revenue generator. Seventy-two percent of the responding administrators indicated they currently offered health promotion programs, although only $48 \%$ submitted information regarding them. Seventy percent said they planned to begin new health promotion programs within the next 12 months, while only $6 \%$ planned to discontinue programs in the next year.
\end{abstract}

Key words: Health promotion programs - Health education programs Hospital programs

*To whom reprint requests should be sent. 


\section{INTRODUCTION}

While much activity and interest in health promotion programming is apparent on the part of Michigan hsopitals, less is known about the range and variety of health promotion efforts. Nor are the attitudes of hospital administrators with respect to hospital-based health promotion well known either. In 1983, the MHA surveyed its 217 member hospitals both to gather subjective information from hospital administrators about health promotion and objective information about existing hospital-based health promotion programs. Of those surveyed, 174 returned responses, representing an $80 \%$ response rate.

The survey was undertaken in an effort to provide some generic information about hospital-based health promotion programs. The results of the survey are presented in order to assist hospital staff in planning new programs and reviewing those already in existence.

The survey was funded as part of a health promotion grant awarded to the Michigan Hospital Association by the W.K. Kellogg Foundation in Battle Creek, Michigan.

\section{METHODS}

The survey instrument was developed in February, 1983, by Deniston, Pack and Beery. It consists of two parts. Part I was sent to the primary hospital administrator at each MHA member hospital. The administrator was asked to answer the questions on Part I. A copy of Part II was to be distributed by the administrator to each program administrator of each health promotion program currently conducted by the hospital. Part II of the survey then provided detailed data about current health promotion programs.

The following definitions of 'health promotion' and 'health promotion program' were provided in the survey instructions. 'Health Promotion' was defined as'. . . any attempt to influence individuals to adopt and maintain healthy lifestyles, frequently requiring the relinquishment of unhealthy behaviors. It includes those activities designed for basically healthy populations in order to reduce the risk of future illness or debilitating conditions. These activities, however, must include more than the mere sharing of health information.'

A health promotion program 'encompasses a variety of coordinated activities designed to achieve behavioral changes in participants.'

The survey was sent at the end of March, 1983, with the request that it be completed and reutrned by April 15th. Shortly before it was sent out, an announcement of the forthcoming survey was placed in the MHA weekly newsletter, Monday Report. A President's Letter from the MHA administrator was enclosed with the survey. The President's Letter told about the health promotion grant the MHA and its member hospitals had received from the W.K. Kellogg Foundation. Each hospital was strongly 
encouraged to return the completed survey as a first step in participating in the health promotion project.

After April 15th, follow-up telephone calls and letters were continued through August 1st, 1984 until $80 \%$ of the surveyed hospitals responded.

\section{RESULTS}

Of the 217 hospitals surveyed, $174(80 \%)$ provided information on their expectations and level of involvement with health promotion programs. Of the 174 responding, 104 (48\%) hospitals provided information on 532 existing health education programs. The programs included 216 (41\%) health promotion programs (according to the definition in the survey instructions), $110(21 \%)$ disease management/patient education, 66 (12\%) safety and first aid instruction, $87(16 \%)$ health screening, and 53 (10\%) other education programs. Apparently, many of the responding hospitals saw any education programs provided for patients/consumers/community participants as 'health promotion'!

\section{PART I - survey results}

Table I reports the questions and responses for Part I of the survey.

Part I also addressed the expectations on the part of individual hospital administrators regarding existing programs. The responses to the latter three questions indicate that hospital administrators expected to provide health promotion services to enhance the hospital's role as a provider of health care services to the community. Ironically, at a time when reimbursement issues are foremost in most administrators' minds, attention to funding of these programs was not reported. This is particularly interesting in that health promotion programs are not usually reimburseable under current reimbursement plans.

\section{PART II - survey results}

Table II lists the various subjecl areas that were covered by the 532 programs submitted. There were additional program descriptions submitted that covered a wide range of activities judged not to constitute formal programs, e.g. speakers bureaus to many short-term topics of general interest. There were not tabulated and are not included in Table II.

Sixty percent of the programs were offered fewer than five times a year. Another $24 \%$ were offered $6-20$ times a year, and $16 \%$ offered 23-100 times/year. Three programs were offered over 100 times a year, for a reported 104, 150 and 500 times, respectively.

Seventeen percent reported average program enrollments of 10 people or less. Another 53\% had enrollments averaging 11-30 people; $11 \%$ had 31- 50 participants; $8 \%$ ranged 50-100 enrollees; and 9\% reported over 100 participants per average program offering. The median enrollment was 20 . 
HOSPITAL EDUCATIONAL PROGRAMMING AND HOSPITAL ADMINISTRATORS' PERCEPTIONS OF PROGRAM PURPOSES; PERCENT OF RESPONDENTS

\begin{tabular}{|c|c|c|c|c|c|}
\hline & \multicolumn{5}{|c|}{ Percentage } \\
\hline & Yes & No & $\begin{array}{l}\text { No } \\
\text { response }\end{array}$ & & \\
\hline $\begin{array}{l}\text { Does your hospital currently offer } \\
\text { health promotion programs: }\end{array}$ & 72 & 28 & 0 & & \\
\hline $\begin{array}{l}\text { Does your hospital plan to begin any } \\
\text { new health promotion programs } \\
\text { within the next } 12 \text { months? }\end{array}$ & 70 & 26 & 4 & & \\
\hline $\begin{array}{l}\text { Do you plan to discontinue any of your } \\
\text { existing programs over the next year? }\end{array}$ & 6 & 84 & 10 & & \\
\hline \multirow{3}{*}{$\begin{array}{l}\text { Have you offered any programs that have } \\
\text { been discontinued? }\end{array}$} & 14 & 80 & 6 & & \\
\hline & High & & & Low & \\
\hline & 1 & 2 & 3 & 4 & response \\
\hline $\begin{array}{l}\text { To what extent is your hospital's } \\
\text { health promotion program(s) } \\
\text { viewed by the hospital as a } \\
\text { public relations/patient } \\
\text { recruitment tool? }\end{array}$ & 31 & 24 & 21 & 5 & 18 \\
\hline $\begin{array}{l}\text { To what extent are they viewed } \\
\text { by the hospital as a revenue } \\
\text { generator? }\end{array}$ & 17 & 5 & 24 & 48 & 22 \\
\hline $\begin{array}{l}\text { To what ex tent are they viewed } \\
\text { by the hospital as a needed } \\
\text { community service? }\end{array}$ & 61 & 14 & 2 & 1 & 22 \\
\hline
\end{tabular}

${ }^{a}$ Most administrators surveyed who indicated they had no current health promotion programs did not respond to these 3 questions.

TABLE II

NUMBER OF PROGRAMS BY SPECIFIC TOPIC, ARRANGED UNDER GENERAL HEADINGS

\begin{tabular}{lr}
\hline Subject & No. program \\
\hline Health promotion & 216 \\
Aerobic exercise & 18 \\
Alcohol abuse prevention & 3 \\
Cancer prevention & 1 \\
Drug abuse prevention & 1 \\
Employee assistance/occupational health & 3 \\
Exercise fields & 2 \\
Exercise, general & 25 \\
General wellness & 21 \\
Healthy heart & 5
\end{tabular}


TABLE II (continued)

Subject

No. program

Mental health

5

Nutrition

Physical conditioning

Smoking cessation

45

Stroke prevention

Weight control

Stress management

Disease management $\quad 110$

Alcohol abuse $\quad 13$

Cancer $\quad 14$

Diabetes $\quad 46$

Heart disease $\quad 16$

Hypertension $\quad 14$

Pain 1

Pulmonary disease 5

Weight control-surgical 1

First aid and safety $\quad 66$

Back strain prevention 2

Cardiopulmonary resuscitation (CPR) $\quad 31$

Child safety/health 2

First aid 8

Hypothermia prevention 1

Infant safety/health $\quad 8$

Injury prevention/general 1

Medication use 4

Poison prevention 6

Sports injury prevention 3

$\begin{array}{ll}\text { Screening } & 87\end{array}$

Cancer 5

Child development 1

Diabetes $\quad 9$

Health fairs $\quad 17$

Health promotion screening $\quad 30$

Heart disease prevention 3

Hypertension $\quad 19$

Speech and hearing 3

Miscellaneous $\quad 53$

Aging 6

Baby sitter class 5

Family planning 2

Home nursing 1

Parenting 5

Prenatal classes $\quad 31$

Sibling class 3

Total programs $\quad 532$ 
Most programs are of limited duration; $13 \%$ of all programs lasted only $1 \mathrm{~h}$. One third involved $2-5 \mathrm{~h}$ of the participant's time. Another $28 \%$ involved $6-10 \mathrm{~h} ; 22 \%$ took $11-20 \mathrm{~h}$; and, $4 \%$ lasted $22-60 \mathrm{~h}$. Only two programs reported more than $60 \mathrm{~h}$ of commitment from the participants. Median duration was $6 \mathrm{~h}$.

The information supplied by Part II of the survey was tabulated for the following subcategories: bed size, hospital district, length of time the program had been offered, staffing patterns and methodologies used, fees, resources, outreach patterns, and follow-up on the programs. These results follow.

\section{Bed size}

Table III shows the response rates and number of educational programs as distributed among the bed size categories. Small hospitals were somewhat less likely to respond, but considerably less likely to report offering programs. However, when programs were offered, they had similar duration and enrollments, regardless of hospital size (detailed tabulations on this and other categories are available upon request). There was a difference in the mix of programs as categorized in Table II; health promotion programs made up only slightly more than $1 / 4$ in hospitals with less than 200 beds but half of reported programs in larger hospitals. We are less certain of this relationship since we wonder if hospitals of different sizes may have interpreted the program definitions differently. An earlier survey of patient education programs [1] found 231 programs reported by 181 hospitals whereas only 110 such programs were reported in this study. We suspect larger hospitals may not have reported all disease management programs; if that is true, the larger hospitals are providing more of both health promotion and patient education programs.

We saw no relationship of hospital size to the number of participants per program (range 20-23) nor to length of program (5-8 h) (detailed tabulations are available from the authors).

\section{TABLE III}

RESPONSE RATE, NUMBER OF PROGRAMS REPORTED, AND MEAN NUMBER OF PROGRAMS PER HOSPITAL BY BED SIZE

\begin{tabular}{clllll}
\hline Bed size & $\begin{array}{l}\text { Hospitals } \\
\text { in state }\end{array}$ & $\begin{array}{l}\% \\
\text { responding } \\
\text { to survey }\end{array}$ & $\begin{array}{l}\% \\
\text { reporting } \\
\text { programs }\end{array}$ & $\begin{array}{l}\text { Mean no. of. } \\
\text { programs } \\
\text { responding } \\
\text { hospital } N\end{array}$ & $\begin{array}{l}\text { Mean no. programs/ } \\
\text { hospital reporting } \\
\text { programs } \\
N\end{array}$ \\
\hline $6-99$ & 102 & 72 & 29 & 2.1 & 5.1 \\
$100-199$ & 39 & 90 & 46 & 2.5 & 4.8 \\
$200-499$ & 65 & 86 & 71 & 4.1 & 5.0 \\
Over 500 & 11 & 91 & 91 & 6.1 & 6.1 \\
& 217 & 80 & 48 & 3.1 & 5.1 \\
\hline
\end{tabular}




\section{Hospital district}

Michigan is divided into eight hospital district councils. The least populous district in terms of population is the Upper Peninsula, where the fewest programs per reporting hospital were reported. All other districts reported an average of 3-4 programs per hospital, with the exception of the West Central District where two programs per hospital were reported.

All districts reported more health promotion programs than any other category except for the Upper Peninsula where nearly equal numbers of programs were reported in each of the five categories. However, Southeastern Michigan hospitals reported nearly as many disease management as health promotion programs. Many of the hospitals in Detroit are large tertiary care centers that focus their attention on helping patients manage diseases. Additionally, there is a Detroit-based health education council that directs much attention to patient education. Examination of program mix by geographic region yields a contingency coefficient of 0.30 , statistically significant at the 0.05 level. Thus this mix of reported programs is related to geographic region.

The median enrollment per program is a relatively constant number of 20. This is true for Southeastern Michigan as well as the Upper Peninsula.

\section{Length of time reported programs offered}

The programs are relatively young. One in 5 is less than 6 months old and over two of every three were developed within the past 2 years.

The median enrollment for the newest programs is higher, 70 , while enrollment is relatively stable for those $6-12$ months, $1-2$ years and over 2 years. The peak enrollment in more recent programs reflects both the newness of some programs as well as the content. For example, several health fairs and 'fun runs' with many participants were held. These programs may be expected to attract more than ordinarily might attend a weight control or similar subject class that is held over several sessions.

Table IV illustrates the recent proliferation of health promotion programs. Forty-four percent of the health promotion programs were initiated within

TABLE IV

\section{NUMBER AND TYPE OF EDUCATIONAL PROGRAM, BY DURATION}

\begin{tabular}{lcllrrr}
\hline $\begin{array}{l}\text { Length of time } \\
\text { program has been } \\
\text { offered }\end{array}$ & $\begin{array}{l}\text { Health } \\
\text { promotion }\end{array}$ & $\begin{array}{l}\text { Disease } \\
\text { management }\end{array}$ & $\begin{array}{l}\text { First aid } \\
\text { and safety }\end{array}$ & Screening & Misc. & Total \\
\hline Time not reported & 2 & N.A. & 2 & 1 & 1 & 6 \\
6 months or less & 48 & 21 & 7 & 14 & 12 & 102 \\
6-12 months & 47 & 21 & 12 & 15 & 7 & 102 \\
12-24 months & 79 & 32 & 21 & 31 & 7 & 170 \\
More than 24 months & 40 & 36 & 24 & 26 & 26 & 152 \\
Total & 216 & 110 & 66 & 87 & 53 & 532 \\
\hline
\end{tabular}

\footnotetext{
${ }^{\mathrm{a}}$ Not applicable.
} 
the previous 12 months and an additional $37 \%$ in the previous year. Only $38 \%$ of the reported disease management programs occurred within the same time interval. While one third of such programs are more than 2 years old, only $18 \%$ of the health promotion programs are so. The highest growth rate for first-aid and safety programs happened in 1981 or earlier. Screening programs showed their highest growth rate around 1982 when $36 \%$ of the reported programs were begun.

There are some relationships between hospital bed size and the length of time programs had been offered. While the larger hospitals have, as noted earlier, the greatest numbers of programs, it appears that the development of new programs is tapering off. The hospitals that are increasing their activities fastest in the past year are those with fewer than 100 beds.

\section{Program staff}

Nurses were staff to $62 \%$ of the programs. As shown in Table V, health educators and nutritionists/dieticians were reported in $42 \%$ of the programs. Other disciplines participated in fewer than $25 \%$ of the programs reported.

With respect to median hours spent in direct teaching by various staff types, auxilians and voluntecrs spent the most time in direct teaching (See Table V). Nurses and social workers spent the most time in course preparation. More hours were spent by hospital staff members developing courses than spent in actual teaching.

Examination of staff in relation to hospital size suggests hospitals tend to use staff they have on payroll regardless of whether the hospital was highly involved in educational programming. More specifically, nurses were used in $73 \%$ of the programs reported by hospitals of 6-99 beds; health

\section{TABLE V}

PROGRAM STAFF: FREQUENCY OF ASSOCIATION AND EXTENT OF INVOLVEMENT

\begin{tabular}{llll}
\hline Staff & $\begin{array}{l}\text { \% of } \\
\text { programs } \\
\text { using } \\
\text { staff } \\
\text { type }\end{array}$ & $\begin{array}{l}\text { Median h } \\
\text { reported } \\
\text { spent in } \\
\text { direct } \\
\text { teaching }\end{array}$ & $\begin{array}{l}\text { Median h reported } \\
\text { spent in course } \\
\text { development }\end{array}$ \\
\hline Nurse & 62 & 4 & 8 \\
Health educator & 42 & 4 & 6 \\
Nutritionist/dietician & 42 & 2 & 4 \\
Physical therapist & 21 & 2 & 3 \\
Social worker & 16 & 2 & 8 \\
Auxilian/volunteer & 15 & 6 & 6 \\
Psychiatrist & 4 & 2 & N.A. \\
Other & 56 & 4 & N.A. \\
\hline
\end{tabular}

\footnotetext{
${ }^{a}$ Not applicable.
} 
educators were less frequently used, appearing in conjunction with only $31 \%$ of the programs reported in these hospitals. As hospitals got larger nurses were involved in a lower proportion of programs, but remain the most frequent discipline in the largest hospitals. Health educators are involved more frequently. However, the same average number of staff were used, regardless of hospital size.

\section{Education methods used}

Program administrators were asked to identify the specific educational methods used (See Table VI). Of the methods, written materials were reported with the highest useage, followed by audio-visual methods. Discussion groups, demonstrations, and one-to-one discussion and/or counseling sessions were listed third, fourth, and fifth, respectively. Role modeling was much less frequently used, as was also true of health hazard risk appraisals and self-contracting. Noticeably absent in the list was lecturing as a method. This method may be included in the 'other' methods that were not specified by respondents.

A total of $43 \%$ of the programs indicated that they developed some of their educational methods in-house. These methods included written materials, audio-visual materials, demonstrations and health hazard/risk appraisals. In large hospitals (over 500 beds), $61 \%$ used materials developed in-house. Other hospitals reported using in-house developed materials in approximately $40 \%$ of their programs. There was no difference between programs offered less than 6 months and programs that had been offered for a longer period of time in terms of their likelihood to develop in house materials. Thirty-nine percent of the programs that were 1-2 years old reported using materials developed in-house; $48 \%$ that were older than 2 years reported using in-house materials.

Programs used an average of five different educational methods. Only $1 \%$ indicated they used all nine methods and 5\% reported using only one method.

\section{TABLE VI}

\section{PERCENT OF EDUCATIONAL PROGRAMS UTILIZING EACH OF SEVERAL TECHNIQUES}

\begin{tabular}{ll}
\hline Methods & \% programs reporting method use \\
\hline Written materials & 87 \\
Audio-visual materials & 78 \\
Discussion groups & 67 \\
Demonstrations & 64 \\
One-to-one discussion/counseling & 57 \\
Role play/modeling & 27 \\
Health hazard risk appraisal & 23 \\
Other methods & 26 \\
\hline
\end{tabular}


The length of time a program had been offered was not associated with the number of educational methods used by the program.

\section{Fees and use of outside resources}

Forty-eight percent of the respondents indicated that a fee was charged in conjunction with their hospital's program. Thirty-eight percent indicated that other sources of revenue for the program were available. There was a slight increase in the tendency to charge fees for newer programs.

Health promotion programs had a relatively consistent fee of $\$ 15.00$ per program (See Table VII). Table VII also shows the average fees charged. Fees ranged from $50 \$$ to $\$ 550$, and $52 \%$ of the programs reported charging nothing. Seventeen percent of all programs charged a fee ranging from $50 \phi$ to $\$ 10 ; 13 \%$ ranged from $\$ 11$ to $\$ 25 ; 10 \%$ ranged from $\$ 30$ to $\$ 95$; and $5 \%$ charged $\$ 100-\$ 550$. Only five charged more than $\$ 175$. Set fees covered a portion of staff time, materials, and advertising, and in some cases, fees were used as a'self-contracting' tool for participants. Some classes reported that a portion of the fee was returned at the end of the course if certain objectives were met by the participant.

Thirty-eight percent of the programs reported using resources that were not hospital based. This included use of instructors from other organizations, materials, and space. Programs in the largest hospitals (54\%) and the smallest (46\%) tended to more often make use of outside of the hospital resources than did medium size hospitals (30\%).

No noticeable trend was detected in the use of outside resources by programs with differing lengths of time offered.

\section{Program outreach into the community: in search of the audience}

Program administrators were asked to indicate whether they specifically targeted any particular group in the community as a potential source of program participants. All indicated that they had a specific audience in mind for their programs. The choices given on the survey were business organizations within the community, schools, parents and families, and, patients and/or hospital employees (internal audience) (See Table VIII).

\section{TABLE VII}

\section{AVERAGE FEES AND PERCENT OF PROGRAMS CHARGING FEE}

\begin{tabular}{lll}
\hline Program type & $\begin{array}{l}\text { Average fee } \\
\text { charged } \$\end{array}$ & $\begin{array}{l}\text { \% programs } \\
\text { charging a fee }\end{array}$ \\
\hline Health promotion & 48.97 & 66 \\
Disease management & 19.75 & 32 \\
First aid/safety & 10.79 & 47 \\
Screening & 46.40 & 25 \\
Other health education & 18.81 & 47 \\
$\quad$ programs & & 48 \\
\hline
\end{tabular}


PERCENT OF PROGRAMS WITH DESIGNATED AUDIENCE, BY TYPE OF PROGRAM

\begin{tabular}{llllll}
\hline $\begin{array}{l}\text { Program } \\
\text { subject }\end{array}$ & $\begin{array}{l}\text { Business/ } \\
\text { industry } \\
\%\end{array}$ & $\begin{array}{l}\text { Community } \\
\text { schools } \\
\%\end{array}$ & $\begin{array}{l}\text { Parents/ } \\
\text { families } \\
\%\end{array}$ & $\begin{array}{l}\text { Hospital } \\
\text { employees } \\
\text { or patients } \\
\%\end{array}$ & $\begin{array}{l}\text { All other } \\
\%\end{array}$ \\
\hline Health promotion & 46 & 37 & 43 & 66 & 66 \\
$\begin{array}{l}\text { Disease management } \\
\text { First aid/safety }\end{array}$ & 16 & 14 & 33 & 85 & 35 \\
$\begin{array}{l}\text { Screening } \\
\text { Other health education } \\
\quad\end{array}$ & 45 & 44 & 58 & 52 & 67 \\
$\quad$ programs & 45 & 26 & 47 & 39 & 79 \\
All programs & 34 & 33 & 46 & 62 & 59 \\
\hline
\end{tabular}

The target audience choices were not mutually exclusive. Health promotion programs were usually directed initially to hospital employees. If successful there, the programs were often expanded to local businesses. Health promotion programs were also oriented to the general community included in the 'all other' category. Program administrators were less inclined to target community schools for health promotion programs than any other specified groups.

As expected, the majority of disease management programs were directed internally to hospital patients, their families and other members of the community that form patient support groups.

First-aid, safety and screening programs were usually oriented to the community at-large. The screening programs probably reflect the inclusion of health fairs in the screening program category.

\section{Follow-up}

Program administrators were asked what (if any) and when follow-up was done. The answers to the later question were vague and infrequent, and so not tabulated. A fourth of programs reported a mailed survey and one in five reported some post-session effort as a telephone follow up. One in 4 reported some other form of follow up. Some programs reported multiple forms of follow up but half reported no follow up at all.

\section{DISCUSSION}

There is definite interest and enthusiasm regarding health promotion and 'wellness' possibilities in the United States this decade. Some informal discussions have touted health promotion as the public health challenge that, if properly attended to, will provide substantial reductions in dis- 
ability and premature death for many people living in developed, industrial countries.

Naturally, health care providers are interested, if not also enthusiastic, about providing health promotion services to reflect new trends as well as new technologies to their communities. Due to the recent efforts of those providing health promotion services, there is real merit in having a nonprovider sort through some of the intents of the provider organizations as well as attempt to review and categorize information about the programs being developed, offered and, in time, those programs being discontinued. This information should be useful to the planners of such services, and of interest for comparative purposes to academics teaching about such services and other organizations and individuals coordinating health promotion needs and services.

The survey done by the Michigan Hospital Association provides information on the level of involvement of Michigan hospitals in health promotion by reviewing the variety of program subject areas, looking at staffing and fee patterns, assessing the growth and participation rates with programs, while also glimpsing the depth and commitment to health promotion programs made by sponsoring hospitals by looking at hours of teaching and planning, variety and number of teaching methods used, and follow-up and program evaluation frequency.

The staffing patterns reviewed indicate that hospitals are using existing clinical staff rather than hiring new specialists. This should come as no surprise in a time when many hospital budgets are constrained by heavy debt and operating costs while also facing new programs such as Medicare's DRG program intended to reduce hospital costs. As health promotion services are yet relatively new services, there is a lack of information about costs of providing, pricing, and public demand for such services. Administrators are therefore careful about the amount of resources, particularly new resources, they can and will commit to health promotion programming.

Hospital boards and administrators, while willing to assign hospital staff to new program responsibilities, seem unsure of what to expect from their programs. They obviously are making few formal program evaluation demands as at most only $53 \%$ of the programs reported using any follow-up methodologies. It was also interesting to see that auxilians and volunteers were involved in $15 \%$ of the reported programs, and spent a substantial amount of time both in direct teaching and course development. It is doubtful that similar findings would be reported in the clinical departments such as the emergency room, pathology or obstetrics departments. It is particularly doubtful that volunteers and auxilians would be used to develop other hospital services, with the possible exception of planning fund raisers for the hospital.

Additionally, there was a broad range of reported programs, including several that obviously did not fit the usual definition of health education. More striking is the fact that over half of the reported programs did not fit the surveyors' provided definition of health promotion. 
It appears that Michigan hospitals are committed to the 'shot gun' approach in providing health promotion programs, figuring that if one shoots enough ammunition that something will be hit. However that approach fails to address the adequacy of the shot: Will it achieve anything in particular with a hit?

The approach is not particularly new, and has been used by other types of organizations that pursued new ideas with more enthusiasm than organization. It also reflects a lack of guidance from more centralized sources. This latter circumstance is due to the time lag between the activities in the field, and the knowledge and understanding of the academicians and similar individuals seeking to impart a sense of order to the field. In time these things will sort out, with successful field approaches being observed and shared with other field members - and a dwindling of the less successful programs. (It should be noted here however that successful programs can not necessarily be equated with program efficacy). However there is need for further knowledge and understanding of these programs and related efforts. It should be valuable, both to those considering offering such programs to enhance their efforts and meet their needs as well as to help insure that health promotion efforts do not pass away as a fad when they should be an important trend with bearing on the health of the public. Similar surveys should continue to be undertaken, and rigorously analyzed to provide insight into hospital-based health promotion activities - that were only glimpsed by the 1983 MHA survey.

\section{CONCLUSION}

There is much interest and activity on the part of Michigan hospitals in health education programs, including health promotion programs. Hospitals wish to provide a service perceived, both by themselves as well as the community, as an important one. At a time when self care, quality of life and cost containment issues are being discussed, health promotion programs are being undertaken more and more frequently by hospitals. However, health promution prograns need clear definition in terms of program expectations, cost to the hospital providing the programs, potential market for the programs, best use of staff currently available within most hospitals, recommended and required staff for efficient and effective health promotion programs (the distinction there also needs to be made), and a potential profit margin that might allow hospitals to prospectively absorb cost and develop new programs. In light of all these issues, this paper has been presented as a description of $\mathbf{5 3 2}$ existing programs self-reported by hospitals in 1983. It was interesting to note that while $72 \%$ of the hospital administrators indicated their hospitals offered health promotion programs currently, only $48 \%$ of the hospitals actually submitted information regarding their programs.

The survey was supported as part of a project funded through the W.K. Kellogg Foundation, Battle Creek, Michigan. The project calls for a repeat 
of the survey in 3 years. At that time it will be interesting to see if there has been an increase in attention given to follow-up, especially if the rate of expansion of health promotion programming continues. Changes in the staffing patterns and fee structure will also be of interest.

\section{ACKNOWLEDGMENT}

The authors wish to thank Ms. Cinda Eltzroth for her help in the preparation of this paper.

\section{REFERENCE}

1 Pack BE, Hendrick RM, Murdock RB, Palma LM: Factors affecting criteria met by hospital-based patient-education programs: A Michigan experience. Pat Educ Couns $1983 ; 5: 76-84$. 